\title{
Targeting Neuroprotection as an Alternative Approach to Preventing and Treating Neuropathic Pain
}

\author{
Thierry Bordet and Rebecca M. Pruss \\ Trophos, Parc Scientifique de Luminy, Luminy Biotech Entreprises, 13288 Marseille, France
}

\begin{abstract}
Summary: Neuropathic pain syndromes arise from dysfunction of the nerve itself, through traumatic or nontraumatic injury. Unlike acute pain syndromes, the pain is long-lasting and does not respond to common analgesic therapies. Drugs that disrupt nerve conduction and transmission or central sensitization, currently the only effective treatments, are only modestly effective for a portion of the patients suffering from neuropathic pain and come with the cost of serious
\end{abstract}

adverse effects. Neurodegeneration, as a reaction to nerve trauma or chronic metabolic or chemical intoxication, appears to be an underlying cause of neuropathic pain. Identifying mechanisms of neurodegeneration and designing neuroprotective therapies is an ambitious goal toward treating or even preventing the development of these disabling disorders. Key Words: Neuropathic pain, neurodegeneration, trophic factors, mitochondria.

\section{INTRODUCTION}

Although unpleasant, acute or transient pain after traumatic injury, surgery, sunburn, or secondary to inflammation usually resolves spontaneously. In the meantime, the pain can be relieved by local anesthetics, anti-inflammatory drugs, or, in the most severe cases, temporary use of mild to strong opiates. In contrast, in addition to traumatic nerve injury (including stroke and spinal cord damage), some chronic diseases such as diabetes, HIV, and varicella zoster infection are associated with a high probability of developing neuropathic pain. In some cases, painful neuropathy may be due to nerve damage caused by the disease itself, or it may develop as an iatrogenic artifact of the treatment. For example, repeated rounds of chemotherapy with microtubule targeting agents or platins and long-term use of HIV-controlling antiretroviral drugs often result in painful neuropathy. ${ }^{1}$ Nerve damage or dysfunction can be demonstrated in these and a number of other syndromes that are associated with chronic pain (e.g., multiple sclerosis), leading to the hypothesis that chronic or neuropathic pain is a symptom of neurodegeneration.

Address correspondence and reprint requests to: Rebecca M. Pruss, Ph.D., Trophos, Parc Scientifique de Luminy, Luminy Biotech Entreprises, Case 931, 13288 Marseille Cedex 9, France. E-mail: rpruss@ trophos.com.
The neurodegeneration may be subtle or undetectable as measured by histological methods, but even without overt signs of neuronal cell death or axon degeneration, neuronal dysfunction can be detected by changes in neural excitability and conduction parameters or gene and protein expression. These changes, as well as loss of specific nerve populations, perturb the coordinated signaling that is important for interpreting sensory stimulation. Peripheral nerve damage or dysfunction can be expected to result in alterations in both neuronal conduction and transmission to those centers that integrate and interpret sensory stimulation. It stands to reason that these painful conditions may respond only to drugs, such as anticonvulsants and anesthetics, that interrupt neuronal conduction or transmission, or to antidepressants, which may normalize central processing of sensory information. Although drugs in these classes have shown modest efficacy and are approved for the treatment of some forms of neuropathic pain, how they work is still far from clear.

Nonetheless, if neurodegeneration is the underlying cause of neuropathic pain, it seems logical to consider neuroprotection as a means either to prevent the onset, control progression or even to reverse the nerve damage leading to these chronic pain syndromes. Neuroprotection would consist of methods that maintain neuronal survival or function in the face of a pathological stress. This stress could include systemic neurotoxic insults 
caused by metabolic disorders or drugs, as well as the effect of nerve damage on otherwise uninjured neighboring neurons.

This review addresses some types of neuropathic pain that may be amenable to neuroprotective approaches. It is speculative regarding the role that neurodegeneration plays in these painful and troubling symptoms and, although far from exhaustive, provides some selected instructive examples that may provoke thoughts on the medical challenge to finding effective treatments of neuropathic pain by targeting neuroprotection.

\section{PAIN CONDITIONS ASSOCIATED WITH NEURODEGENERATION AND POSSIBLE CAUSES}

\section{Diabetes}

Most persons with diabetes will develop some degree of peripheral neuropathy, starting a decade or more after disease onset, and 10-30\% will develop neuropathic pain. A recent study of the prevalence and severity of painful neuropathy in type 2 diabetic patients found that $24 \%$ have neuropathic pain, and more than $75 \%$ consider their pain moderate or severe according to established neurological and pain scales. ${ }^{2}$

Hyperglycemia with resulting oxidative stress is the underlying cause of the neurovascular complications of diabetes and is the major risk factor for both neuropathy and neuropathic pain. ${ }^{3-5}$ Indeed, the interdependence of nerves and blood vessels leads to a vicious cycle in which changes in the vasculature that result in increased vasoconstriction restrict nutrient and oxygen supply to the nerves, leading to dysregulation of nerve input to the vasculature. High intracellular glucose favors glycolysis and the polyol cycle, both leading to an increased supply of the reduced agents NADH (nicotinamide adenine dinucleotide reduced form) and $\mathrm{FADH}_{2}$ (flavin adenine dinucleotide reduced form). Excess accumulation of these electron donors can then lead to overproduction of reactive oxygen species by the mitochondrial electron transport chain. Excess glucose can also be covalently attached to proteins producing age-related glycation endproducts, and receptors for these endproducts can also contribute to oxidative stress. Reduced supply of neurotrophic factors from surrounding tissue also increases neuronal oxidative damage.

Various therapeutic strategies targeting oxidative stress include treatment with antioxidants such $\alpha$-lipoic acid or vitamins $\mathrm{E}$ and $\mathrm{C}$, aldose reductase inhibitors, and inhibitors of age-related glycation endproduct formation or its receptors. Despite some promising results in small clinical trials, however, long-term studies have failed because of lack of efficacy or because of adverse effects (see the review by Vincent et al. ${ }^{3}$ ). Mitochondrial dysfunction induced by oxidative stress may be a major culprit in the development of neuropathy and neuropathic pain in chronic diabetes. ${ }^{4}$

\section{HIV and antiretroviral therapies}

Painful sensory neuropathy has become the most common neurological complication of infection with human immunodeficiency virus type 1 (HIV-1). ${ }^{6}$ Distal sensory polyneuropathy (DSP) is directly caused by HIV-1 infection, and its severity is associated with advancing immunosuppression (low CD4 cell count) and viral load. ${ }^{7,8}$ Antiretroviral toxic neuropathy (ATN) resulted from the neurotoxicity of components of highly active antiretroviral therapy (HAART). ${ }^{9,10}$ Both DSP and ATN share similar clinical features, including burning pain and symmetrical paresthesias. Both are characterized by a dying back axonal degeneration of long axons in distal regions, loss of unmyelinated fibers, and reduced intraepidermal nerve fiber density that correlates with disease severity and progression. ${ }^{1-13}$

Among HAART components, dideoxynucleoside reverse transcriptase inhibitors (NRTIs, mainly didanosine [ddI], and stavudine, or d4T) were significantly associated with a heightened risk for symptomatic $\mathrm{ATN}^{14}$; however, a combination with immune-mediated mechanisms triggered by HIV infection seems to be critical in the development of their neurotoxicity. Indeed, high doses of NRTIs are not sufficient to induce ATN in mice, and similar doses in transgenic mice for HIV coat protein gp120 induced distal degeneration of unmyelinated sensory axons. ${ }^{15}$ Whether protease inhibitors have to be considered as a risk factor for ATN is still controversial. Neurotoxicity of indinavir was demonstrated in vitro on dorsal root ganglia (DRG) cultures, and an increased risk for ATN was reported with exposure to indinavir in two independent studies. ${ }^{10,16}$ Nonetheless, evaluation of protease inhibitors as an independent risk factor for ATN in a larger cohort (1159 HIV-infected individuals) did not confirm their toxicity, except for amprenavir and lopinavir, which may slightly increase the risk for ATN. ${ }^{17}$ Finally. the increase in survival of HIV-infected patients with prolonged medication exposure is associated with an increased risk of neuropathy. ${ }^{13,16}$

The pathogenesis of ATN remains poorly understood, although mitochondrial toxicity of NRTIs has been known for many years, based on their inhibition of the mitochondrial DNA polymerase- $\gamma{ }^{18}$ Indeed, increased numbers of abnormal mitochondria in nerves and significantly reduced cellular mtDNA content were evidenced in patients treated with ddC (zalcitabine). ${ }^{19} \mathrm{Be}-$ yond inhibition of the mitochondrial DNA polymerase- $\gamma$, NRTIs have direct effect on mitochondrial membrane potential inducing energy failure and subsequent axonal degeneration in DRG cultures without neuronal loss. ${ }^{20,21}$ Their toxicity could be even aggravated by pre-existing HIV-mediated mitochondrial defects. ${ }^{22}$ Using feline immu- 
nodeficiency virus (FIV)-infected animals, Zhu et al. ${ }^{21}$ demonstrated that treatment with ddI exacerbated FIV neurotoxic effects, increasing pain sensation and reducing epidermal density of nerve endings. Development of ATN induced by ddI was also associated with mitochondrial injury on neurons and reduced brain-derived neurotrophic factor (BDNF) production by Schwann cells in DRGs of FIV-infected animals. Given that BDNF improves mitochondrial function, modulation of its expression may be part of the pathogenesis of ATN. ${ }^{23,24}$

Altogether, preclinical and clinical data highlight the convergent pathogenic effects of HIV infection and antiretroviral drugs to mediate distal axonal degeneration and pain. More than cell death at the neuronal level, local changes at the axonal level such as mitochondrial dysfunction or changes in neurotrophic factors expression may play a major role in the pathogenesis of DSP and ATN.

\section{Chemotherapy-induced peripheral neuropathy}

Chemotherapy-induced peripheral neuropathy (CIPN) is the main dose-limiting adverse effect of commonly used chemotherapeutic agents, including platinum drugs, taxanes, epothilones, and vinca alkaloids, but also of newer agents such as bortezomib and lenalidamide. ${ }^{25}$ The degree and type of peripheral neuropathy depends on the chemotherapy drug, with incidence ranging from $10 \%$ to $90 \%$ of patients, and with platinum drugs such as oxaliplatin being the most toxic. ${ }^{26}$

For most drugs the risk increases with cumulative dose. Typically, the clinical presentation reflects an axonal peripheral neuropathy with glove-and-stocking distribution sensory loss, combined with features suggestive of nerve hyperexcitability, including paresthesia, dysesthesia, and pain. Most of the time, peripheral neuropathy reverses if the drug dose is reduced or if the treatment is stopped; however, in some cases recovery from symptoms is incomplete, and a long period of regeneration is required to restore function. ${ }^{27}$ To date, no drug is available to reliably prevent or cure CIPN. Furthermore, recently approved drugs for treatment of diabetic neuropathic pain, such as gabapentin and pregabalin, provided no benefit in CIPN, suggesting the involvement of specific disease mechanisms. ${ }^{28}$

The mechanisms underlying CIPN are diverse and depend on the drug. Platinum agents (cisplatin, oxaliplatin, carboplatin) induce neuronal apoptosis in the DRG through the formation of DNA-platinum complexes and early p38 and ERK1/2 activation. ${ }^{29,30}$ Recently, James et al. ${ }^{31}$ also reported that cisplatin induced neurite degeneration of primary rat neurons in line with the observed axonal neuropathy in patients. Notably, the neurotoxicity of cisplatin can be alleviated by inhibiting the Rho signaling pathway.
The toxicity profile of oxaliplatin differs from those of other platinum compounds; it induces an acute neurotoxicity characterized by a rapid onset of cold-induced distal dysesthesia, followed by a chronic sensory peripheral neuropathy when treatment is continued. ${ }^{32}$ Recently, the acute neurotoxicity of oxaliplatin was associated with its interference with neuron voltage-gated sodium channels through one of its metabolites, oxalate, a calcium chelator. ${ }^{33-35}$

Microtubule-targeting agents (e.g., paclitaxel, vincristine) display axonal toxicity, with the longest axons being the first affected. ${ }^{36}$ For paclitaxel, studies in animal models using high doses initially supported the hypothesis that the drug's neurotoxicity arises from disruption of microtubules and impairment of axonal transport, but numerous reports now refute this idea. ${ }^{37-40}$ Indeed, low doses of paclitaxel caused allodynia and hyperalgesia in rats without inducing degeneration of myelinated and unmyelinated axons in the sciatic nerve and roots. ${ }^{41,42}$ Degeneration was rather confined to receptor terminals of the sensory fiber in the skin and was associated with prominent activation of cutaneous Langerhans cells. ${ }^{43}$ The earliest defect observed in both C-fibers and myelinated axons was the appearance of swollen and vacuolated mitochondria. ${ }^{42}$ In addition, these mitochondrial changes resolved when pain behavior decreased, suggesting that abnormalities in axonal mitochondria directly contribute to peripheral neuropathy and pain. Similarly, peripheral nerve biopsies from patients with vincristine-evoked painful neuropathy revealed axonal and mitochondrial swelling, whereas microtubule alterations were not evidenced. ${ }^{44}$ Such results are in agreement with the reported mitochondrial toxicity of microtubule-targeting drugs in human cell lines, and strongly argue in favor of energy failure as the main cause of nerve hyperexcitability and degeneration observed in paclitaxel-induced peripheral neuropathy. ${ }^{45,46}$

\section{Postherpetic neuralgia}

Postherpetic neuralgia (PHN) is a neuropathic pain syndrome triggered by peripheral nerve damage due to reactivation of latent varicella zoster virus in sensory nerve cell bodies. The reactivated virus moves to the skin via afferent nerve fibers and may also enter nerve fibers projecting to the spinal cord. The PHN syndrome is defined as pain persisting for 3 or more months after onset of the skin rash; it can occur in up to $50 \%$ of patients, depending on age. ${ }^{47,48}$ The pain, which is usually localized to zoster-infected areas of the skin, can include constant, deep-burning pain, brief recurrent shooting or shock-like pain, and tactile allodynia. ${ }^{49} \mathrm{Al}-$ lodynia can exist in the presence or absence of sensory loss. ${ }^{50}$

Although the condition stems from varicella zoster virus damage to peripheral nerves, central sensitization 
also plays an important role in PHN. Peripheral and central demyelination may be implicated, as well as nerve damage. As in other types of nerve injury, changes in the expression or activation of voltage-dependent sodium channels and NMDA receptors may underlie sensory nerve hyperexcitability and central sensitization, respectively. (Note that, although neuroprotection is the subject of this review, recent clinical trials suggest the opposite approach: using high-concentration topical capsaicin to ablate sensory nerve terminals offers an effective treatment for PHN. ${ }^{51}$ ) Ultimately, neuroprotection will be afforded by preventing PHN through vaccination against herpes zoster virus. ${ }^{52,53}$

\section{Multiple sclerosis}

According to the National Multiple Sclerosis Society (http://www.nationalmssociety.org), almost half of all people with multiple sclerosis (MS) are troubled by chronic pain, which can include acute burning, tingling, shooting, or stabbing pain, trigeminal neuralgia, L'Hermitte's sign (a brief, stabbing, electric-shock-like sensation running down the spine brought on by bending the head forward), or dysesthesia, a burning, aching, or girdling around the body. In MS, pain originates mainly from damage in the CNS and shares similarities with central pain caused by stroke and spinal cord injury. ${ }^{54-56}$ Mechanisms underlying central pain are still largely unknown but lesions affecting the spinothalamo-cortical track appear as a risk factor for developing central pain. ${ }^{57,58}$ Although all approved treatments for MS attempt to reduce the inflammatory, autoimmune process that destroys central myelin, they do little to halt the progression of the disease, which is due to degeneration of demyelinated axons. Neuroprotective therapies are badly needed, either to directly prevent axon and nerve degeneration or to stimulate remyelination. ${ }^{59,60}$

\section{NEURODEGENERATION: MECHANISMS \& POSSIBLE TARGETS}

\section{Trophic factors: pros and cons}

If neuropathic pain is a consequence of neurodegeneration, then neurotrophic factors could provide a neuroprotective strategy. The role and regulation of the major neurotrophic factors implicated in neuropathy and pain (nerve growth factor, NGF; BDNF; neurotrophin 3, NT3; and glial cell line-derived neurotrophic factor, GDNF), and their receptors, have been thoroughly reviewed. $^{61}$

NGF and its receptor, neurotrophic tyrosine kinase type 1 (TrkA), are required for the development of sympathetic and sensory neurons, and reduced levels of NGF are implicated in diabetic and chemotherapy-induced neuropathy. NGF administration can prevent development of neuropathy and reduction in pain thresholds in animal models of diabetic and chemotherapy-induced neuropathic pain. However, increased expression and release of NGF is one mechanism underlying inflammatory pain, and administration of NGF to naïve animals lowers pain thresholds. NGF-induced hyperalgesia may be due to its ability to induce expression of BDNF and neuromediators such as calcitonin gene-related peptide (CGRP) and substance P. NGF and TrkA signaling also increases expression, activation properties, or axonal distribution of sodium channels in DRG neurons. Indeed, BDNF signaling through TrkB is involved in central sensitization in chronic pain states and has recently been shown to be required for the establishment of persistent pain states (but not for acute pain responses). ${ }^{62}$ Although NGF may be beneficial for treating or preventing neuropathy, it appears to be contraindicated for reversing pain. In fact, clinical trials of NGF in patients with diabetic neuropathy and HIV-induced neuropathy either failed to provide sufficient evidence of efficacy or resulted in painful adverse effects (Table 1).

Paradoxically, strategies to antagonize NGF using neutralizing antibodies, soluble TrkA receptors, or TrkA antagonists are also being considered for the treatment of chronic pain. ${ }^{63}$ In contrast to BDNF and NGF, GDNF appears to have generally beneficial effects in animal models of nerve injury-induced painful neuropathy, without producing hyper or hypoalgesia in naïve animals. The GDNF family of trophic factors and their receptors (the receptor tyrosine kinase RET in combination with a family of GPI-linked coreceptors) are widely expressed in the central and peripheral nervous system. Targeting those expressed in DRG nociceptors (artemin and RET-GRF $\alpha 3$ ) may be a future strategy for treating painful neuropathies. $^{64}$

\section{Excitotoxicity: not just glutamate}

Excitotoxicity most commonly refers to glutamate-induced neurotoxicity mediated by ligand-gated ion channels, particularly those permeable to calcium. Glutamate receptors, and NMDA receptors in particular, may be involved in central sensitization to peripheral hyperexcitability. ${ }^{65}$ Although glutamate receptors would be relevant targets for both neuroprotection and symptomatic pain relief, they are widely distributed in the nervous system, and antagonists have cognitive and psychotomimetic effects. ${ }^{66}$

In addition to glutamate receptors, other ion channels may also play a role in excitotoxicity leading to axon and nerve terminal degradation. TRPV1 (transient receptor potential cation channel, subfamily $\mathrm{V}$, member 1) receptors are heat-activated nonselective cation channels expressed on sensory nerve endings; they transduce burning pain when activated by capsaicin, a compound found in chili peppers. ${ }^{67}$ Chronic activation of TRPV1 receptors by capsaicin leads to calcium overload and degen- 
Table 1. Neuroprotective Agents Explored or Still in Clinical Development for Treating Peripheral Neuropathies with Documented Results or Listed at ClinicalTrials.gov

\begin{tabular}{lcccc}
\hline Compounds and Trials & Company & Latest Development Status & Mechanism \\
\hline $\begin{array}{c}\text { Recombinant human nerve } \\
\text { growth factor (rhNGF) }\end{array}$ & Genentech and clinician-sponsored & Phase III; stopped & Neurotrophic factor \\
\hline
\end{tabular}

A randomized trial in 1019 diabetic patients to receive either rhNGF or placebo for 48 weeks failed to confirm the earlier indications of efficacy. ${ }^{148}$

NCT00000842: A Phase II, Double-Blind Trial of Recombinant Human Nerve Growth Factor for Treatment of HIV-Associated Sensory Neuropathy. Failed to demonstrate efficacy of NGF; painful adverse effects were dose limiting for NGF. ${ }^{149}$

\begin{tabular}{|c|c|c|c|}
\hline $\begin{array}{l}\text { Recombinant human brain } \\
\text { derived neurotrophic } \\
\text { factor (rhBDNF) }\end{array}$ & Genentech & $\begin{array}{l}\text { Phase II; no recent } \\
\text { update }\end{array}$ & Neurotrophic factor \\
\hline
\end{tabular}

A double-blind placebo-controlled clinical trial of recombinant human brain-derived neurotrophic factor (rhBDNF) in diabetic polyneuropathy (30 patients): some improvement in cool detection threshold when compared with baseline. ${ }^{150}$

\begin{tabular}{|c|c|c|c|}
\hline $\begin{array}{l}\text { PROCRIT (epoietin alfa; } \\
\text { recombinant human } \\
\text { erythropoietin) }\end{array}$ & $\begin{array}{l}\text { Johnson \& Johnson } \\
\text { Pharmaceutical }\end{array}$ & Phase II & Neurotrophic factor \\
\hline
\end{tabular}

NCT00267007: A Randomized, Double-Blind, Placebo-Controlled, Multicenter, 18 Week Pilot Study to Investigate the Neuroprotective Effect of PROCRIT (Epoetin Alfa) on the Development of Peripheral Neuropathy in Patients Receiving Combination Taxane and Platinum-Based Chemotherapy for Cancer (33 patients); study terminated because of slow recruitment.

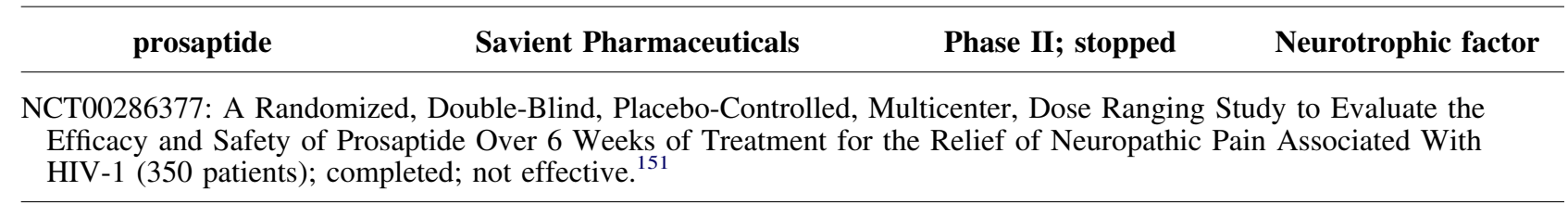

\begin{tabular}{|c|c|c|c|}
\hline $\begin{array}{c}\text { Leteprinim potassium } \\
\text { (Neotrofin, AIT-082, } \\
\text { SPI-205) }\end{array}$ & $\begin{array}{c}\text { Spectrum } \\
\text { Pharmaceuticals/NeoTherapeutics }\end{array}$ & $\begin{array}{l}\text { Phase II; no recent } \\
\text { update }\end{array}$ & Neurotrophin enhancer \\
\hline
\end{tabular}

NCT00041795: A Multi-Center, Double-Blind, Randomized, Placebo-Controlled Study of Neotrofin to Treat Patients With Sensory or Motor Neuropathy Caused by Chemotherapy for Cancer (50 patients); completed; no published results.

\begin{tabular}{llll}
\hline Xaliproden (SR57746A) & Sanofi-Aventis & Phase III; active & Neurotrophin enhancer \\
\hline
\end{tabular}

NCT00272051: A Multicenter Randomized Double-Blind Placebo Controlled Phase III Study of the Efficacy of Xaliproden in Reducing the Neurotoxicity of the Oxaliplatin and 5-FU/LV Combination in First-Line Treatment of Patients With Metastatic Colorectal Carcinoma (MCRC) (620 patients). An overall CIPN rate of 73-74\% was reported in the two groups, with a lower incidence of grade 3 CIPN, 17\% vs 11\%, favoring the xaliproden arm; however, xaliproden did not reduce the overall incidence of neurotoxicity, but rather shifted $5 \%$ of patients from grade 3 to grade 2 of neurotoxicity. The use of xaliproden in this trial was not associated with a higher cumulative oxaliplatin dose or a longer time on therapy. ${ }^{138}$

NCT00305188: A Multicenter, Randomized Double-Blind Placebo Controlled Phase III Study of the Efficacy of Xaliproden in Preventing the Neurotoxicity of Oxaliplatin in First-Line Treatment of Patients With Metastatic Colorectal Cancer Treated With Oxaliplatin/5-FU/LV (900 patients); active not recruiting; results end 2009.

NCT00603577: A Multi-Center, Randomized, Double Blind, Placebo Controlled Phase III Study to Assess the Efficacy of Xaliproden in Patients With Oxaliplatin-Induced Peripheral Sensory Neuropathy (PSN) Following Adjuvant Chemotherapy for Colon Cancer (244 patients); active and recruiting; results end 2010.

(Table continues) 
Table 1. Continued

\begin{tabular}{cccc}
\hline Compounds and Trials & Company & Latest Development Status & Mechanism \\
\hline MCC-257 & Mitsubishi Pharma & Phase II; no recent & Neurotrophin enhancer \\
update
\end{tabular}

NCT00307749: A Phase II, Randomized, Double-Blind, Placebo-Controlled, 24-Week Dose Finding Study to Evaluate the Efficacy and Safety of $20 \mathrm{mg}, 40 \mathrm{mg}$ and $80 \mathrm{mg}$ of MCC-257 in Patients With Mild to Moderate Diabetic Polyneuropathy (420 patients); completed; no published results.

TAK-128

Takeda/Mitsubishi Pharma

Phase II; stopped

Myelin formation accelerator

NCT00756041: an Open-Label, Multi-Center Study to Evaluate the Safety of Long-Term Administration of TAK-128 in Subjects With Mild to Moderate Diabetic Peripheral Neuropathy (221 patients); completed; lack of efficacy.

NCT00229437: A Phase 2, Double-Blind, Randomized, Placebo-Controlled, Dose-Ranging Study to Evaluate the Efficacy and Safety of Three Doses of TAK-128 in Subjects With Mild to Moderate Diabetic Peripheral Neuropathy (343 patients); completed; no published results.

SSR180575 Sanofi-Aventis $\quad \begin{gathered}\text { Phase II; } \\ \text { completed/stopped }\end{gathered} \quad$ PBR ligand

NCT00502515: A Multi-Center, Randomized, Double-Blind, Placebo Controlled Study of the Effect of SSR180575 at Two Doses for 24 Weeks Treatment on the Rate of Regeneration of Epidermal Nerve Fibers in Patients With Mild Diabetic Peripheral Neuropathy (270 patients); completed; results 2009.

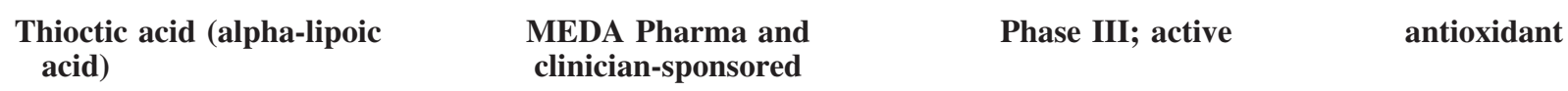

Diabetic polyneuropathy; a 2-year multicenter randomized double-blind placebo-controlled trial (ALADIN II); some improvements in nerve conduction in a subset of patients. ${ }^{152}$

NCT00328601: Assessment of Efficacy and Safety of Thioctic Acid in the Oral Treatment of Symptomatic Diabetic Neuropathy (SYDNEY 2) Randomised, Double-Blind, Placebo-Controlled Multicentre Trial With 4 Parallel Groups (170 patients); completed. Oral treatment with alpha-lipoic acid for 5 weeks improved neuropathic symptoms and deficits in patients with diabetic polyneuropathy. An oral dose of $600 \mathrm{mg}$ once daily appears to provide the optimum risk-tobenefit ratio. ${ }^{153}$

NCT00477607: Prevention of Cisplatin Ototoxicity with the Antioxidant Alpha-Lipoic Acid; under recruitment.

NCT00112996 \& NCT00705029: Prevention of Cisplatin- or Oxaliplatin-Induced Peripheral Neuropathy with AlphaLipoic Acid: A Placebo-Controlled Phase III Trial; under recruitment.

NCT00079807: Painful HIV Neuropathy: Treatment With Alpha-Lipoic Acid. A phase II placebo-controlled study to evaluate the effects of daily oral alpha-lipoic acid supplements $(600 \mathrm{mg}$, three times per day) plus standard medical care in the treatment of painful HIV-associated neuropathy over a 24-week period (60 patients); completed in 2008.

\begin{tabular}{cccc}
\hline Glutamine & clinician-sponsored & Phase III & energy supply \\
\hline
\end{tabular}

NCT00195013: A Randomized Placebo-Controlled Trial of Glutamine to Reduce the Signs and Symptoms of Peripheral Neuropathy in Breast Cancer Patients With a Mild Peripheral Neuropathy Receiving Paclitaxel Chemotherapy (50 patients); under recruitment.

\begin{tabular}{ccc}
\hline Vitamin E & clinician-sponsored & Phase III \\
\hline NCT00363129: The Use of Vitamin E for Prevention of Chemotherapy Induced Peripheral Neuropathy: A Phase III \\
Double-Blind Placebo Controlled Study (200 patients); study ongoing, but not recruiting. \\
(Table continues)
\end{tabular}


Table 1. Continued

\begin{tabular}{|c|c|c|}
\hline Compounds and Trials & Latest Development Status & Mechanism \\
\hline Amifostine trihydrate & clinician-sponsored & neuroprotective agent \\
\hline \multicolumn{3}{|c|}{$\begin{array}{l}\text { NCT00058071: A Randomized Phase III Trial of Amifostine vs. No Treatment for Platinum Induced Peripheral } \\
\text { Neuropathy (100 patients); completed in } 2008 . \\
\text { NCT00078845: Phase II Trial of Subcutaneous Amifostine for Reversal of Persistent Paclitaxel-Induced Peripheral } \\
\text { Neuropathy ( } 40 \text { patients); completed. } \\
\text { NCT00601198: Phase II Study of the Efficacy of Amifostine (Ethyol) in Reducing the Incidence and Severity of } \\
\text { Oxaliplatin-Induced Neuropathy in Patients With Colorectal Cancer ( } 97 \text { patients); active and recruiting; results } 2009 .\end{array}$} \\
\hline
\end{tabular}

\begin{tabular}{ccc}
\hline Acetyl-L-carnitine & clinician-sponsored & Phase III; active \\
\hline NCT00050271: An Open-Label, Dose-Escalation Pilot Study of Acetyl-L-Carnitine for the Treatment of \\
Dideoxynucleoside-Associated Distal Symmetric Peripheral Neuropathy (36 patients); study ongoing, but not recruiting. \\
NCT00775645: Randomized Placebo-Controlled Trial of Acetyl-L-Carnitine (ALC) for the Prevention of Taxane Induced \\
Neuropathy Phase III. Study in women with stage I, stage II, or stage IIIA breast cancer undergoing chemotherapy (380 \\
patients); not yet recruiting; results 2012. \\
NCT00751205: (REASON) Double-Blind, Randomized Phase II Study to Evaluate the Safety and Efficacy of Acetyl-L- \\
Carnitine in the Prevention of Sagopilone-Induced Peripheral Neuropathy (140 patients); results 2010. \\
\hline
\end{tabular}

$\begin{array}{llll}\text { Olesoxime (TRO1962) } & \text { Trophos } & \text { Phase II; active } & \text { neuroprotective agent }\end{array}$

NCT00496457: A Double-Blind, Randomized, Multicenter Study With 500 mg QD of TRO19622 Versus Placebo in Patients With Painful Peripheral Diabetic Neuropathy (180 patients); completed; well tolerated, no improvement compared with placebo.

NCT00876538: A Double Blind, Placebo Controlled Study of the Effect of $330 \mathrm{mg}$ QD of TRO19622 in the Treatment of Chemotherapy Induced Peripheral Neuropathy. An exploratory Phase II study of pain, dysesthesia and neuropathy in patients with taxane-induced peripheral neuropathy (40 patients); under recruitment.

NCT numbers refer to entries at http://www.clinicaltrials.gov.

$\mathrm{CIPN}=$ chemotherapy-induced peripheral neuropathy; HIV = human immunodeficiency virus; LV $=$ leucovorin (folinic acid); 5-FU $=$ 5-fluorouracil.

eration of sensory nerve terminals; in this case, neurodegeneration has been shown to reduce pain in animal models and in humans. ${ }^{68}$ Various forms of capsaicin are being explored and developed clinically to treat chronic pain syndromes (e.g., NGX-4010, ALGRX-4975). Because TRPV1 receptors are upregulated as well as activated during inflammation, TRPVI antagonists have been hotly pursued as analgesics by pharmaceutical and biotech companies. However, TRPV1 receptors appear to play an important role in central thermal regulation, and the potential for TRPV1 antagonists to induce hyperthermia is an unacceptable adverse effect that is likely to limit their future clinical development. ${ }^{69}$

Increased C-fiber excitability, which has been found in diverse neuropathic pain syndromes, is often correlated with changes in voltage-gated sodium channel expression, distribution, or firing threshold in peripheral sensory neurons. ${ }^{70-72}$ Although much attention has been focused on sensory neuron selective sodium channels such as $\mathrm{Na}_{\mathrm{v}} 1.7, \mathrm{Na}_{\mathrm{v}} 1.8$, and $\mathrm{Na}_{\mathrm{v}} 1.9$ as drug targets to treat pain, their role in neuropathic pain remains controversial. Mutations in $\mathrm{Na}_{\mathrm{v}} 1.7$ are found in congenital pain syndromes, and knock-down or inhibition of $\mathrm{Na}_{\mathrm{v}} 1.8$ has been reported to reduce neuropathic pain behavior in animals. ${ }^{73-76}$ Surprisingly, neuropathic pain is still present in mice lacking $\mathrm{Na}_{\mathrm{v}} 1.7$ or $\mathrm{Na}_{\mathrm{v}} 1.8$ (established using a $\mathrm{Na}_{\mathrm{v}} 1.8$ driven knock-out strategy) and neuropathic pain behavior is even maintained in mice in which nearly all $\mathrm{Na}_{\mathrm{v}} 1.8$ positive nociceptors have been ablated. ${ }^{77-79}$ Because $\mathrm{Na}_{\mathrm{v}} 1.8$-expressing nociceptors also express and release BDNF in the spinal cord, perhaps it is the absence of BDNF that changes pain behavior in mice lacking $\mathrm{Na}_{\mathrm{v}}$ 1.8-positive sensory neurons, given the role of BDNF and TrkB in the establishment of some types of persistent pain behavior (although maybe not all types of neuropathic pain-at least not in mice). ${ }^{62}$

Nevertheless, increased expression of sodium channels on nerve terminals and axons would be one mechanism contributing to hyperexcitability and, through increased depolarization, increased intracellular calcium due to activation of voltage-dependent calcium channels. As in multiple sclerosis, in which ectopic expression of sodium channels is believed to contribute to long-term axonal degeneration, long-term overactivation of sensory nerve sodium channels may also contribute to neurodegeneration in neuropathic pain. ${ }^{80}$ Although these changes have been documented in diverse animal models, it is not clear whether similar changes in sodium channel expression are present clinically. Nonetheless, local anesthetics, which block voltage-gated sodium channels by binding 
to a site within the pore formed by the $\alpha$-subunit, are used to treat various pain syndromes, including some types of neuropathic pain. If sodium channel hyperexcitability leading to calcium overload is an underlying component of neurodegeneration, local anesthetics might provide neuroprotection; however, the potential for neurologic and cardiac adverse effects limits their usefulness for this purpose.

In axons and nerve terminals, mitochondria play a major role in maintaining ion homeostasis after membrane depolarization by generating ATP to drive plasma membrane $\mathrm{Na}^{+} / \mathrm{K}^{+}$ATPase and buffering intracellular calcium. Loss of mitochondrial capacity to provide ATP or to take up calcium could be a factor contributing to the sensory nerve fiber degeneration that occurs in neuropathic pain conditions.

\section{Mitochondrial dysfunction}

Oxidative damage resulting from disease or chemical intoxication (chemotherapeutics, alcohol abuse, HAART) occurs in large part because of reactive oxygen species produced by the mitochondrial electron transport chain. Ironically, mitochondria themselves are targets of oxidative damage to their DNA and membranes, both of which lead to mitochondrial dysfunction. The mitochondrial permeability transition pore (mPTP), a protein complex that regulates mitochondrial integrity, is sensitive to thiol oxidation, which facilitates calcium-induced mitochondrial permeability transition. ${ }^{81}$

Proteins that contribute to mPTP and permeability transition include the voltage-dependent anion channel (VDAC), the translocator protein (TSPO; previously known as peripheral benzodiazepine receptor, $\mathrm{PBR}$ ), the adenine nucleotide translocator (ANT), for which specific thiols have been identified, ${ }^{82}$ and cyclophilin $\mathrm{D}$, a prolyl-isomerase that interacts with ANT. Cyclophilin D is the target of Cyclosporin A, a blocker of calcium-induced mitochondrial permeability transition. ${ }^{83,84}$ Decreased growth factor signaling through Akt with resulting increased GSK3 $\beta$ activation leads to dissociation of hexokinase from VDAC and increased probability of mitochondrial permeability transition and apoptosis, and it can also increase sensitivity to chemotherapeutic agents. ${ }^{85}$

Microtubule-targeted chemotherapeutic agents also favor mitochondrial permeability pore transition by modulating tubulin-VDAC interaction, ${ }^{86}$ and some HAARTs may affect the mPTP by binding to ANT. Swollen and vacuolated mitochondria have been observed clinically and in animal models of diabetes and chemotherapyinduced neuropathic pain. ${ }^{42,44,87-89}$ Oxidative stress in diabetic nerve has been suggested to trigger mitochondrial-mediated local apoptosis in nerve terminals leading to axon degradation. ${ }^{4}$ However, given that the DRG cell bodies are up to a meter or more away from the nerve terminal, this may not lead to DRG cell death. Loss of nerve terminal-target interaction and mitochondrial supplied energy for retrograde transport and signaling may, however, induce many of the long-term changes in gene and protein expression changes seen after axotomy.

\section{Changes in undamaged nerves induced by neurodegeneration}

Although it is obvious that traumatic injury can lead to transient or permanent nerve damage, the behavior of undamaged nerves can be modified by the loss of their neighbors. Changes in gene expression (including upregulation of sodium channels, TRPV1 receptors, BDNF and neuropeptides such as substance $\mathrm{P}$ and CGRP) have been found in uninjured DRG neurons after axotomy, either as a result of relatively greater abundance of trophic factors or because of inflammatory responses to damaged tissue. ${ }^{90-93}$ Perhaps the combination of damage-induced degeneration and changes in spared neurons distinguishes the neuropathic pain mechanisms after nerve injury from other more systemic causes of neurodegeneration, such as diabetes, chemotherapy, or HAART treatment.

\section{THERAPEUTIC APPROACHES TO TARGETING NEUROPROTECTION}

All approved drugs and most of the therapeutic approaches under development aim to reduce symptoms of neuropathic pain, but neuroprotection or even neurorestoration would be even more desirable. Only a few drugs or other agents with direct or indirect neurotrophic activity have been explored or are currently under development for the treatment of peripheral neuropathy (Table 1). Only drugs still under development are detailed here.

\section{Acetyl-L-carnitine: mechanism, efficacy in animal models and the clinic}

Acetyl-L-carnitine (ALC), the acetyl ester of L-carnitine, plays an essential role in the metabolism of long chain free fatty acids. Beyond its classical role in energy metabolism, ALC exhibits many others properties, including antioxidant and neuroprotective properties. ${ }^{94-99}$ Repeated treatment with ALC also promotes nerve regeneration after nerve axotomy. ${ }^{100}$ Reduced levels of ALC were associated with nerve alterations in diabetes and in HIV. ${ }^{101,102}$ In diabetic animals, ALC treatment normalizing plasma and nerve L-carnitine levels prevented motor nerve conduction velocity slowing, reduced lipid peroxidation, and restored $\mathrm{Na}^{+} / \mathrm{K}^{+}$ATPase activity. ${ }^{103-107}$ Both prophylactic and therapeutic treatment with ALC also corrected the thermal hypoalgesia in diabetic mice. ${ }^{108}$ In animal models of CIPN, ALC administration promoted the recovery of nerve conduction velocity and significantly prevented or reversed the neuropathic pain syndrome evoked by vincristine, cisplatin, and paclitaxel. ${ }^{109-112}$ 
Whether mechanisms underlying neuroprotective effects of ALC might be responsible for its analgesic properties is still unclear. In vitro, neuroprotective effects of ALC were associated with upregulation of NGF and its receptor. ${ }^{113-115}$ In a rat model of chronic constriction injury-induced peripheral neuropathy, treatment with ALC reduced cytochrome $c$ release and caspase-3 activation and induced X-linked inhibitor of apoptosis protein (XIAP) expression. ${ }^{116}$ Such effects might be mediated through the maintenance of key mitochondrial functions by ALC. ${ }^{97,117}$ In paclitaxel-induced painful neuropathy, efficacy of ALC was associated with a reduced incidence of swollen and vacuolated mitochondria in C-fiber. ${ }^{118}$ In addition, a more direct effect might explain acute analgesic effects of ALC through upregulation of mGluR2 receptors and downstream activation of endogenous cholinergic activity. ${ }^{119-122}$

In clinical use, ALC is safe and well tolerated. ${ }^{123}$ Two large-scale trials have been conducted supporting some clinical efficacy of ALC for the treatment of diabetic peripheral neuropathy. ${ }^{124}$ Consistent reduction in pain, however, seems to require long-term treatment ( $>1$ year) and high doses of ALC (>3000 mg daily). ${ }^{125}$ Efficacy of ALC was also reported in two pilot trials in patients with paclitaxel or cisplatin-induced neuropathy. In both trials, improvement in the sensory neuropathy grade ranged between $60 \%$ to $73 \%$ of the patients and persisted after ALC treatment. ${ }^{126,127}$ A large randomized placebo-controlled phase III trial is planned to start studying ALC to prevent neuropathy in women with breast cancer undergoing taxane chemotherapy (ClinicalTrials.gov NCT00775645). Similar exploratory studies were conducted in HIV-induced neuropathies and reported some benefit of long-term treatment with ALC. ${ }^{128,129}$ Some other studies are still ongoing (ClinicalTrials. gov NCT00225160). Interestingly, Valcour et al. ${ }^{130}$ reported no differences in density of intraepidermal nerve fibers or in mtDNA copies per cell after 3000 mg ALC daily for 24 weeks, whereas improvements in neuropathic pain were noted, as previously observed in a preclinical study. ${ }^{118}$ Although promising, these results will have to be confirmed in adequately powered placebo-controlled studies to ascertain the potential of ALC to be effective to treat or even prevent painful peripheral neuropathies.

\section{Olesoxime: discovery, mechanism, efficacy in animal models and the clinic}

Olesoxime (TRO19622) is a cholesterol-oxime compound originating from the proprietary library of Trophos (Marseille, France). Identified for its survival-promoting properties for motor neurons in culture, ${ }^{131}$ olesoxime has been shown to inhibit both intrinsic and extrinsic neuronal death pathways (unpublished data). Beyond neuroprotective properties, olesoxime also promoted nerve re- generation in a number of in vitro and in vivo models of neurodegeneration. Olesoxime bound directly to two components of the mitochondrial permeability transition pore, VDAC and TSPO. Recent observations also suggest that olesoxime targets tubulin, which has been shown to be in close association with VDAC in mitochondria. ${ }^{86,132}$ The current working hypothesis on the mechanism of action of olesoxime is in favor of a tight regulation of mitochondrial pore opening through interactions with these proteins.

Olesoxime significantly reduced axonal degeneration and accelerated recovery of motor nerve conduction in a model of peripheral neuropathy induced by crushing the sciatic nerve, which motivated further exploration in other preclinical models of peripheral neuropathy. ${ }^{131}$ Daily oral administration of olesoxime improved motor nerve conduction impaired in streptozotocin-induced diabetic rats and also reversed neuropathic pain behavior as early as the first administration. ${ }^{133}$ Olesoxime also reversed tactile allodynia in chemotherapy-induced (vincristine-induced) painful peripheral neuropathy, but had had no analgesic activity per se in formalin- or chronic constriction injury-mediated neuropathic pain models. ${ }^{133}$ In paclitaxel-treated rats, olesoxime also reversed mechano-allodynia and mechano-hyperalgesia in both preventive and prophylactic treatment paradigms and significantly reduced the amount of paclitaxel-induced sensory terminal arbor degeneration (unpublished data). Mitochondrial dysfunction was proposed to be a common mechanism for both painful diabetic and chemotherapy-induced neuropathies, which supports the presumed olesoxime mechanism of action. ${ }^{4,42,89}$ However, how modulation of mitochondrial function may explain the acute effects of olesoxime on neuropathic pain remains to be determined.

Orally administered, olesoxime is well tolerated and has an excellent clinical safety profile in humans. Its efficacy was evaluated in a multicenter, randomized, double-blind, placebo-controlled phase IIa clinical trial including 187 patients with painful peripheral diabetic neuropathy. Although olesoxime treatment $(500 \mathrm{mg}$ daily, p.o., for 6 weeks) was very well tolerated in this patient population, the primary endpoint of the trial, a significant decrease in mean pain score as measured on the Likert scale, was not met. These disappointing results raise the question of the predictability of preclinical acute models for diabetic peripheral neuropathy induced by streptozotocin, which may not reflect the pain syndrome associated with chronic diabetes in humans. ${ }^{134}$ Based on preclinical results in both vinca alkaloid- and taxane-induced painful neuropathies, an exploratory phase IIa study was launched in patients with paclitaxelinduced neuropathy to test reversion of pain syndromes and improvement in nerve conduction after olesoxime treatment. Efficacy results are expected in 2010. 


\section{Nonpeptide neurotrophic factor modulators}

Many drugs shown to stimulate endogenous neurotrophic factor expression have been developed and tested in peripheral neuropathies (Table 1). Among these, xaliproden (SR 57746A; 1-[2-(naphth-2-yl)ethyl]-4-(3-trifluoromethylphenyl)-1,2,5,6-tetrahydropyridine $\mathrm{HCl}$ ), which is a synthetic $5-\mathrm{HT}_{1 \mathrm{~A}}$ receptor agonist and an inducer of NGF synthesis, possesses neurotrophic activity in a variety of neurodegenerative models in vivo, including peripheral neuropathies. ${ }^{135-137}$ Notably, xaliproden was reported to lessen oxaliplatin-mediated neuropathy in a large, randomized, double-blind, placebo-controlled phase III study $(n=649) .{ }^{138,139}$ Although the use of xaliproden in this trial was not associated with a higher cumulative oxaliplatin dose or with a longer time on therapy, patients in the xaliproden arm had a significant (39\%) risk reduction of developing grade 3/4 neuropathy. A phase III trial in approximately 900 patients is ongoing to confirm these results (NCT00305188), as well as a trial in $\sim 250$ subjects to assess the effect of xaliproden to treat the peripheral sensory neuropathy resulting from oxaliplatin-based chemotherapy (NCT00603577).

MCC-257, an orally active sialic acid derivative, augmented NGF activity in cultured dorsal root ganglia and has neuroprotective properties in diabetic peripheral nerves. ${ }^{140}$ Its safety and efficacy was evaluated in a phase II, randomized, double-blind, placebo-controlled trial in 420 patients with mild to moderate diabetic polyneuropathy (NCT00307749). Results were not disclosed.

Leteprinim (Neotrofin, AIT-082; further developed as SPI-205) induces expression of several neurotrophic factors in various areas of the brain and spinal cord and prevented depletion of NGF in plantar foot skin and sciatic nerve of diabetic rats. ${ }^{141}$ SPI-205 is under clinical development for treatment of chemotherapy-induced neuropathy (http://www.spectrumpharm.com).

TAK-428 enhances neurotrophic factor production and is under development by Takeda Pharmaceutical (Osaka, Japan) for the treatment of diabetic neuropathy. It is currently in phase II in the European Union and in the United States.

\section{TSPO ligands (SSR180575)}

The peripheral benzodiazepine receptor (PBR), recently renamed translocator protein $18 \mathrm{kDa}$ (or TSPO, as noted earlier in this review), is an outer mitochondrial membrane protein implicated in mitochondrial cholesterol uptake and steroidogenesis; it is a well known target for neuroprotection. ${ }^{142-144}$ SSR180575 (7-chloro- $N, N, 5$-trimethyl-4-oxo-3-phenyl3,5 -dihydro- $4 H$-pyridazino[4,5- $b$ ]indole-1-acetamide) is a novel specific and potent TSPO ligand improving functional recovery in rat models of peripheral neuropathy. ${ }^{145,146}$ SSR180575 increased pregnenolone accumu- lation in the brain and sciatic nerve $(100 \%$ increase at 3 $\mathrm{mg} / \mathrm{kg}$, i.p.), suggesting that its neuroprotective effects are steroid-mediated. SSR180575 is under current clinical investigation in patients with mild diabetic peripheral neuropathy (NCT00502515).

\section{CONCLUSIONS}

Neuropathic pain, as the term implies, is due to an intrinsic pathology of the nerve. This distinguishes it from acute or inflammatory pain arising from outside the nerve, through release of neuromediators or cytokines from neighboring cells that directly and transiently activate a range of receptors and ligand-gated ion channels. Preventing neuropathic pain in cases in which it is most prevalent seems, at least on the face of it, a feasible goal. Nonetheless, much more needs to be known about the mechanisms of neurodegeneration in each condition to know what neuroprotective strategy is likely to be most effective. Although studying a treatment to assess its ability to reverse a condition is not a regulatory or technical challenge, identifying targets or critical processes with the intention of reversing neuropathic pain is an enormous conceptual challenge that has so far effectively stymied drug discovery.

In the case of diabetes, the disease process leading to neuropathy and pain is slow and probably involves not only axonal damage that may misalign sensory signaling but also causes, over time, long-term changes in central processing of sensory information, including seemingly irreversible changes in gene expression. These changes occur gradually, and may not be perceptible before the damage or central plasticity has gone too far to be reversed. If neuropathic pain is similar to other types of neurodegeneration, oxidative stress combined with calcium overload triggered by various factors may be a common underlying mechanism. Although antioxidants such as $\alpha$-lipoic acid, ALC, and Vitamins E and C have been studied in a large number of neurodegenerative conditions, including painful neuropathies, with some promising results (Table 1), none have yet to be approved to treat these indications. Thus, either an antioxidant alone is not able to provide sufficient benefit or the treatment does not reach the appropriate target at high enough concentration or for long enough a time to provide relief.

Antioxidants are believed to improve mitochondrial function by reducing mitochondrial membrane or DNA damage. Other drugs targeting mitochondria in clinical development are TSPO ligands that reduce apoptosis correlated with increased mitochondrial cholesterol uptake and steroidogenesis. A trial of SSR180575 in 270 diabetic patients to determine whether this drug can enhance regeneration after capsaicin-induced nerve terminal lesion has recently been completed. This exploratory 
study might have been the prelude for a larger and longer clinical trial of its ability to reverse established diabetic neuropathy; however, this compound has recently been dropped from the clinical development pipeline, so one can speculate that either the clinical results were not compelling or the development plan was considered too long, complicated, and costly.

Although mitochondrial protection seems attractive as a general mechanism, it may not be the only strategy and may not be sufficiently effective on its own or in all conditions. For example, olesoxime did not improve pain compared with placebo in patients with painful diabetic neuropathy, although no measurement of the effect on neuropathy was made in this short, 6-week trial (Table 1). A study of olesoxime in a small number of patients with paclitaxel-induced neuropathic exploring both pain and neuropathy endpoints began recruiting patients early in 2009. Besides mitochondrial protection, other downstream mediators of stress signaling arising from mitochondrial dysfunction, such as p38 kinase, may also be useful targets, either alone or in combination with other approaches.

Testing a promising neuroprotective drug in patients with a chronic disease such as diabetes prior to the onset of neuropathic pain is, unfortunately, not practical because of the long time course (decades) and variable incidence of painful neuropathy, which, though common, occurs in only some $30 \%$ of patients; a study involving several hundred patients over a decade would be necessary to demonstrate efficacy without some way of identifying which patients would be most at risk of developing neuropathic pain. Thus, the first trials of neuroprotective agents to treat chronic painful neuropathies are likely to be in conditions in which the cause and effect are more closely linked in time, such as PHN and chemotherapy-induced neuropathic pain. Because gabapentin and its analog pregabalin, along with topical lidocaine and most recently NGX-4010 are all approved for the treatment of PHN, treatments targeting neuroprotection will be confounded by the need to perform trials in patients treated with these agents that either block or ablate nerve conduction or transmission.

Chemotherapy-induced painful neuropathy may be the simplest indication in which to test a neuroprotective therapeutic. It is the direct consequence of the chemotherapeutic regime, the time course of onset is shorter (compared with diabetes) and more predictable, in that it is related to the cumulative dose; however, it develops only in a subset of patients depending on the type of chemotherapeutic agent (as discussed above). Therefore, clinical trials to test whether neuroprotection might prevent the onset of painful neuropathy could seem at first glance quite feasible. Nonetheless, because the incidence of severe pain is variable, a large number of patients are likely to be required if the beneficial effects are modest or occur in only a subpopulation. For example, the two studies with xaliproden to prevent oxaliplatin-induced neuropathies recruited 650 and 900 patients, respectively (Table 1). In the case of chemotherapy-induced neuropathy, the initial recruitment has to take into account the loss of patients over the course of the trial (cancer-related deaths and discontinuation of treatment because of neuropathy) to be sure that at the end of the trial the number of subjects who have completed the trial provide sufficient power to conclude efficacy.

Another consideration to take into account is whether the mechanism of action of a neuroprotective drug may adversely affect the efficacy of the chemotherapy. Preclinical studies in tumor xenograft models are required before initiating clinical trials, in which responder rates can be used to assure no negative consequence of the neuroprotective agent. Finally, when a neuroprotective treatment is available for testing, enrollment criteria for the clinical trial may be very narrow, such that few patients qualify: for example, the type of chemotherapy used, whether the patient has received previous types of chemotherapy, and potential to complete the trial (i.e., life expectancy). Such restrictions can make the time to recruit the defined patients longer than a company or funding agency can support.

Testing whether neuroprotection may reverse or accelerate recovery from chemotherapy-induced painful neuropathy is also straightforward: it is necessary only to identify subjects who have completed their course of chemotherapy and have developed neuropathic pain. Although this sounds simple, execution is complicated: enrollment criteria must be tightly defined, making few patients eligible, and the cancer must be sufficiently controlled to allow patients to stop chemotherapy during the course of the trial for as long as 6 months or more (first the time to complete the pre-trial screening process and then treatment for at least 3 months). Nevertheless, both prevention and treatment of chemotherapy-induced painful neuropathy are of medical concern, because this condition is a major reason for patients to stop chemotherapy. By allowing patients to continue their cancer treatment longer, an effective neuroprotective drug could increase both survival and quality of life.

Although reversing or preventing the neurodegenerative processes that underlie neuropathic pain by targeting neuroprotection is a path worth exploring, the challenges are enormous. For companies, the ultimate objective is a treatment that will be effective in the maximum number of subjects. Unfortunately, the various pain syndromes collectively labeled neuropathic pain have diverse underlying causes, including trauma, viral infection, inflammation, metabolic disturbances, and therapeutic or other chemical intoxication. Each represents only a niche market, and targeting therapies to one indication does not mean they will treat another. Chemotherapy-induced 
painful neuropathies are refractory to current drugs approved for painful diabetic neuropathy or PHN.

A noteworthy central mediator of various types of nontraumatic stress-induced painful neuropathies appears to be mitochondrial dysfunction, due to and then contributing to oxidative damage and calcium overload. Given that targeting mitochondrial dysfunction is a strategy to treat other neurodegenerative diseases, such as Alzheimer's disease, the massive research and development efforts dedicated to this indication will, we can hope, lead to a breakthrough allowing targeting neuroprotection for neuropathic pain syndromes. ${ }^{147}$

Acknowledgments: We thank Julien Veys for invaluable documentation support, finding and retrieving critical information and references used in this review. We also thank Janet Winter and Noelle Callizot for reading the manuscript and their many helpful comments and suggestions.

\section{REFERENCES}

1. Cata JP, Weng HR, Lee BN, Reuben JM, Dougherty PM. Clinical and experimental findings in humans and animals with chemotherapy-induced peripheral neuropathy. Minerva Anestesiol 2006;72: $151-169$

2. Davies M, Brophy S, Williams R, Taylor A. The prevalence, severity, and impact of painful diabetic peripheral neuropathy in type 2 diabetes. Diabetes Care 2006;29:1518-1522.

3. Vincent AM, Russell JW, Low P, Feldman EL. Oxidative stress in the pathogenesis of diabetic neuropathy. Endocr Rev 2004;25: 612-628.

4. Leinninger GM, Edwards JL, Lipshaw MJ, Feldman EL. Mechanisms of disease: mitochondria as new therapeutic targets in diabetic neuropathy. Nat Clin Pract Neurol 2006;2:620-628.

5. Tomlinson DR, Gardiner NJ. Glucose neurotoxicity. Nat Rev Neurosci 2008;9:36-45.

6. McArthur JC, Brew BJ, Nath A. Neurological complications of HIV infection. Lancet Neurol 2005;4:543-555.

7. Childs EA, Lyles RH, Selnes OA, et al. Plasma viral load and CD4 lymphocytes predict HIV-associated dementia and sensory neuropathy. Neurology 1999;52:607-613.

8. Tagliati M, Grinnell J, Godbold J, Simpson DM. Peripheral nerve function in HIV infection: clinical, electrophysiologic, and laboratory findings. Arch Neurol 1999;56:84-89.

9. Schifitto G, McDermott MP, McArthur JC, et al. Markers of immune activation and viral load in HIV-associated sensory neuropathy. Neurology 2005;64:842-848.

10. Lichtenstein KA, Armon C, Baron A, Moorman AC, Wood KC, Holmberg SD; HIV Outpatient Study Investigators. Modification of the incidence of drug-associated symmetrical peripheral neuropathy by host and disease factors in the HIV outpatient study cohort. Clin Infect Dis 2005;40:148-157.

11. Ferrari S, Vento S, Monaco S, et al. Human immunodeficiency virus-associated peripheral neuropathies. Mayo Clin Proc 2006; 81:213-219.

12. Pardo CA, McArthur JC, Griffin JW. HIV neuropathy: insights in the pathology of HIV peripheral nerve disease. J Peripher Nerv Syst 2001;6:21-27.

13. Simpson DM, Kitch D, Evans SR, et al.; ACTG A5117 Study Group. HIV neuropathy natural history cohort study: assessment measures and risk factors. Neurology 2006;66:1679-1687.

14. Cherry CL, Skolasky RL, Lal L, et al. Antiretroviral use and other risks for HIV-associated neuropathies in an international cohort. Neurology 2006;66:867-873.

15. Keswani SC, Jack C, Zhou C, Höke A. Establishment of a rodent model of HIV-associated sensory neuropathy. J Neurosci 2006; 26:10299-10304.
16. Pettersen JA, Jones G, Worthington C, et al. Sensory neuropathy in human immunodeficiency virus/acquired immunodeficiency syndrome patients: protease inhibitor-mediated neurotoxicity. Ann Neurol 2006;59:816-824.

17. Ellis RJ, Marquie-Beck J, Delaney P, et al.; CHARTER Group. Human immunodeficiency virus protease inhibitors and risk for peripheral neuropathy. Ann Neurol 2008;64:566-572.

18. Cherry CL, McArthur JC, Hoy JF, Wesselingh SL. Nucleoside analogues and neuropathy in the era of HAART. J Clin Virol 2003;26:195-207.

19. Dalakas MC, Semino-Mora C, Leon-Monzon M. Mitochondrial alterations with mitochondrial DNA depletion in the nerves of AIDS patients with peripheral neuropathy induced by $2^{\prime} 3^{\prime}-$ dideoxycytidine (ddC). Lab Invest 2001;81:1537-1544.

20. Keswani SC, Chander B, Hasan C, Griffin JW, McArthur JC, Hoke A. FK506 is neuroprotective in a model of antiretroviral toxic neuropathy. Ann Neurol 2003;53:57-64.

21. Zhu Y, Antony JM, Martinez JA, et al. Didanosine causes sensory neuropathy in an HIV/AIDS animal model: impaired mitochondrial and neurotrophic factor gene expression. Brain 2007;130:2011-2023.

22. Robinson B, Li Z, Nath A. Nucleoside reverse transcriptase inhibitors and human immunodeficiency virus proteins cause axonal injury in human dorsal root ganglia cultures. J Neurovirol 2007;13:160-167.

23. El Idrissi A, Trenkner E. Growth factors and taurine protect against excitotoxicity by stabilizing calcium homeostasis and energy metabolism. J Neurosci 1999;19:9459-9468.

24. Markham A, Cameron I, Franklin P, Spedding M. BDNF increases rat brain mitochondrial respiratory coupling at complex I, but not complex II. Eur J Neurosci 2004;20:1189-1196.

25. Wolf S, Barton D, Kottschade L, Grothey A, Loprinzi C. Chemotherapy-induced peripheral neuropathy: prevention and treatment strategies. Eur J Cancer 2008;44:1507-1515.

26. Wilkes G. Peripheral neuropathy related to chemotherapy. Semin Oncol Nurs 2007;23:162-173.

27. Hausheer FH, Schilsky RL, Bain S, Berghorn EJ, Lieberman F. Diagnosis, management, and evaluation of chemotherapy-induced peripheral neuropathy. Semin Oncol 2006;33:15-49.

28. Rao RD, Michalak JC, Sloan JA, et al.; North Central Cancer Treatment Group. Efficacy of gabapentin in the management of chemotherapy-induced peripheral neuropathy: a phase 3 randomized, double-blind, placebo-controlled, crossover trial (N00C3). Cancer 2007;110:2110-2118.

29. McDonald ES, Randon KR, Knight A, Windebank AJ. Cisplatin preferentially binds to DNA in dorsal root ganglion neurons in vitro and in vivo: a potential mechanism for neurotoxicity. Neurobiol Dis 2005;18:305-313.

30. Scuteri A, Galimberti A, Maggioni D, et al. Role of MAPKs in platinum-induced neuronal apoptosis. Neurotoxicology 2009;30: 312-319.

31. James SE, Burden H, Burgess R, et al. Anti-cancer drug induced neurotoxicity and identification of Rho pathway signaling modulators as potential neuroprotectants. Neurotoxicology 2008;29: 605-612.

32. Graham J, Mushin M, Kirkpatrick P. Oxaliplatin. Nat Rev Drug Discov 2004;3:11-12.

33. Grolleau F, Gamelin L, Boisdron-Celle M, Lapied B, Pelhate M, Gamelin E. A possible explanation for a neurotoxic effect of the anticancer agent oxaliplatin on neuronal voltage-gated sodium channels. J Neurophysiol 2001;85:2293-2297.

34. Adelsberger H, Quasthoff S, Grosskreutz J, Lepier A, Eckel F, Lersch C. The chemotherapeutic oxaliplatin alters voltage-gated $\mathrm{Na}^{+}$channel kinetics on rat sensory neurons. Eur J Pharmacol 2000;406:25-32.

35. Gamelin L, Capitain O, Morel A, et al. Predictive factors of oxaliplatin neurotoxicity: the involvement of the oxalate outcome pathway. Clin Cancer Res 2007;13:6359-6368.

36. Quasthoff S, Hartung HP. Chemotherapy-induced peripheral neuropathy. J Neurol 2002;249:9-17.

37. Apfel SC, Lipton RB, Arezzo JC, Kessler JA. Nerve growth factor prevents toxic neuropathy in mice. Ann Neurol 1991;29: 87-90. 
38. Cavaletti G, Cavalletti E, Montaguti P, Oggioni N, De Negri O, Tredici G. Effect on the peripheral nervous system of the shortterm intravenous administration of paclitaxel in the rat. Neurotoxicology 1997; 18:137-145.

39. Cavaletti G, Tredici G, Braga M, Tazzari S. Experimental peripheral neuropathy induced in adult rats by repeated intraperitoneal administration of taxol. Exp Neurol 1995;133:64-72.

40. Authier N, Gillet JP, Fialip J, Eschalier A, Coudore F. Description of a short-term taxol-induced nociceptive neuropathy in rats. Brain Res 2000;887:239-249.

41. Polomano RC, Mannes AJ, Clark US, Bennett GJ. A painful peripheral neuropathy in the rat produced by the chemotherapeutic drug, paclitaxel. Pain 2001;94:293-304.

42. Flatters SJ, Bennett GJ. Studies of peripheral sensory nerves in paclitaxel-induced painful peripheral neuropathy: evidence for mitochondrial dysfunction. Pain 2006;122:245-257.

43. Siau C, Xiao W, Bennett GJ. Paclitaxel- and vincristine-evoked painful peripheral neuropathies: loss of epidermal innervation and activation of Langerhans cells. Exp Neurol 2006;201:507-514.

44. Thant M, Hawley RJ, Smith MT, et al. Possible enhancement of vincristine neuropathy by VP-16. Cancer 1982;49:859-864.

45. Evtodienko YV, Teplova VV, Sidash SS, Ichas F, Mazat JP. Microtubule-active drugs suppress the closure of the permeability transition pore in tumour mitochondria. FEBS Lett 1996;393:86-88.

46. André N, Braguer D, Brasseur G, et al. Paclitaxel induces release of cytochrome $c$ from mitochondria isolated from human neuroblastoma cells. Cancer Res 2000;60:5349-5353.

47. Helgason S, Petursson G, Gudmundsson S, Sigurdsson JA. Prevalence of postherpetic neuralgia after a first episode of herpes zoster: prospective study with long term follow up. BMJ 2000; 321:794-796.

48. Kost RG, Straus SE. Postherpetic neuralgia: pathogenesis, treatment, and prevention. N Engl J Med 1996;335:32-42.

49. Rowbotham MC, Fields HL. Post-herpetic neuralgia: the relation of pain complaint, sensory disturbance, and skin temperature. Pain 1989;39:129-144.

50. Fields HL, Rowbotham M, Baron R. Postherpetic neuralgia: irritable nociceptors and deafferentation. Neurobiol Dis 1998;5: 209-227.

51. Backonja M, Wallace MS, Blonsky ER, et al.; NGX-4010 C116 Study Group. NGX-4010, a high-concentration capsaicin patch, for the treatment of postherpetic neuralgia: a randomised, doubleblind study [Erratum in: Lancet Neurol 2009;8:31]. Lancet Neurol 2008; 7:1106-1112.

52. Christo PJ, Hobelmann G, Maine DN. Post-herpetic neuralgia in older adults: evidence-based approaches to clinical management. Drugs Aging 2007;24:1-19.

53. Sampathkumar P, Drage LA, Martin DP. Herpes zoster (shingles) and postherpetic neuralgia. Mayo Clin Proc 2009;84:274-280.

54. Osterberg A, Boivie J, Thuomas KA. Central pain in multiple sclerosis: prevalence and clinical characteristics. Eur J Pain 2005; 9:531-542.

55. Boivie J, Leijon G, Johansson I. Central post-stroke pain: a study of the mechanisms through analyses of the sensory abnormalities. Pain 1989;37:173-185.

56. Finnerup NB, Jensen TS. Spinal cord injury pain: mechanisms and treatment. Eur J Neurol 2004;11:73-82.

57. Bowsher D. Central pain: clinical and physiological characteristics. J Neurol Neurosurg Psychiatry 1996;61:62-69.

58. Österberg A, Boivie J. Central pain in multiple sclerosis: sensory abnormalities. Eur J Pain 2009 Apr 8; [Epub ahead of print].

59. Lubetzki C, Williams A, Stankoff B. Promoting repair in multiple sclerosis: problems and prospects. Curr Opin Neurol 2005;18: 237-244.

60. Lopez-Diego RS, Weiner HL. Novel therapeutic strategies for multiple sclerosis: a multifaceted adversary. Nat Rev Drug Discov 2008;7:909-925.

61. Sah DW, Ossipo MH, Porreca F. Neurotrophic factors as novel therapeutics for neuropathic pain. Nat Rev Drug Discov 2003;2: $460-472$.

62. Wang X, Ratnam J, Zou B, England PM, Basbaum AI. TrkB signaling is required for both the induction and maintenance of tissue and nerve injury-induced persistent pain. J Neurosci 2009;29:5508-5515.

63. Hefti FF, Rosenthal A, Walicke PA, et al. Novel class of pain drugs based on antagonism of NGF. Trends Pharmacol Sci 2006; 27:85-91.

64. Gardell LR, Wang R, Ehrenfels C, et al. Multiple actions of systemic artemin in experimental neuropathy. Nat Med 2003;9: 1383-1389.

65. Brenner GJ, Ji RR, Shaffer S, Woolf CJ. Peripheral noxious stimulation induces phosphorylation of the NMDA receptor NR1 subunit at the PKC-dependent site, serine-896, in spinal cord dorsal horn neurons. Eur J Neurosci 2004;20:375-384.

66. Ma QP, Woolf CJ. Noxious stimuli induce an $N$-methyl-D-aspartate receptor-dependent hypersensitivity of the flexion withdrawal reflex to touch: implications for the treatment of mechanical allodynia. Pain 1995;61:383-390.

67. Caterina MJ, Schumacher MA, Tominaga M, Rosen TA, Levine JD, Julius D. The capsaicin receptor: a heat-activated ion channel in the pain pathway. Nature 1997;389:816-824.

68. Szallasi A, Blumberg PM. Vanilloid (capsaicin) receptors and mechanisms. Pharmacol Rev 1999;51:159-212.

69. Gavva NR, Bannon AW, Surapaneni S, et al. The vanilloid receptor TRPV1 is tonically activated in vivo and involved in body temperature regulation. J Neurosci 2007;27:3366-3374.

70. Waxman SG, Dib-Hajj S, Cummins TR, Black JA. Sodium channels and pain. Proc Natl Acad Sci U S A 1999;96:7635-7639.

71. Gold MS, Weinreich D, Kim CS, et al. Redistribution of $\mathrm{Na}_{\mathrm{V}} 1.8$ in uninjured axons enables neuropathic pain. J Neurosci 2003;23: $158-166$.

72. Fang X, Djouhri L, McMullan S, et al. trkA is expressed in nociceptive neurons and influences electrophysiological properties via $\mathrm{Na}_{\mathrm{v}} 1.8$ expression in rapidly conducting nociceptors. J Neurosci 2005;25:4868-4878.

73. Cox JJ, Reimann F, Nicholas AK, et al. An SCN9A channelopathy causes congenital inability to experience pain. Nature 2006; 444:894-898.

74. Fertleman CR, Baker MD, Parker KA, et al. SCN9A mutations in paroxysmal extreme pain disorder: allelic variants underlie distinct channel defects and phenotypes. Neuron 2006;52:767-774.

75. Lai J, Gold MS, Kim CS, et al. Inhibition of neuropathic pain by decreased expression of the tetrodotoxin-resistant sodium channel, $\mathrm{Na}_{\mathrm{v}}$ 1.8. Pain 2002;95:143-152.

76. Ekberg J, Jayamanne A, Vaughan $\mathrm{CW}$, et al. $\mu \mathrm{O}$-conotoxin MrVIB selectively blocks $\mathrm{Na}_{\mathrm{v}} 1.8$ sensory neuron specific sodium channels and chronic pain behavior without motor deficits. Proc Natl Acad Sci U S A 2006;103:17030-17035.

77. Nassar MA, Stirling LC, Forlani G, et al. Nociceptor-specific gene deletion reveals a major role for $\mathrm{Na}_{\mathrm{v}} 1.7$ (PN1) in acute and inflammatory pain. Proc Natl Acad Sci U S A 2004;101:1270612711.

78. Nassar MA, Levato A, Stirling LC, Wood JN. Neuropathic pain develops normally in mice lacking both $\mathrm{Na}_{\mathrm{v}} 1.7$ and $\mathrm{Na}_{\mathrm{v}} 1.8$. Mol Pain 2005;1:24.

79. Abrahamsen B, Zhao J, Asante CO, et al. The cell and molecular basis of mechanical, cold, and inflammatory pain. Science 2008; 321:702-705.

80. Waxman SG. Axonal conduction and injury in multiple sclerosis: the role of sodium channels. Nat Rev Neurosci 2006;7:932-941.

81. Petronilli V, Costantini P, Scorrano L, Colonna R, Passamonti S, Bernardi P. The voltage sensor of the mitochondrial permeability transition pore is tuned by the oxidation-reduction state of vicinal thiols: increase of the gating potential by oxidants and its reversal by reducing agents. J Biol Chem 1994;269:16638-16642.

82. McStay GP, Clarke SJ, Halestrap AP. Role of critical thiol groups on the matrix surface of the adenine nucleotide translocase in the mechanism of the mitochondrial permeability transition pore. Biochem J 2002;367:541-548.

83. Veenman L, Shandalov Y, Gavish M. VDAC activation by the 18 $\mathrm{kDa}$ translocator protein (TSPO), implications for apoptosis. J Bioenerg Biomembr 2008;40:199-205.

84. Leung AW, Halestrap AP. Recent progress in elucidating the molecular mechanism of the mitochondrial permeability transition pore. Biochim Biophys Acta 2008;1777:946-952. 
85. Pastorino JG, Hoek JB. Regulation of hexokinase binding to VDAC. J Bioenerg Biomembr 2008;40:171-182.

86. Carré M, André N, Carles G, et al. Tubulin is an inherent component of mitochondrial membranes that interacts with the voltage-dependent anion channel. J Biol Chem 2002;277:3366433669.

87. Lowell BB, Shulman GI. Mitochondrial dysfunction and type 2 diabetes. Science 2005;307:384-387.

88. Leinninger GM, Backus C, Sastry AM, Yi YB, Wang CW, Feldman EL. Mitochondria in DRG neurons undergo hyperglycemic mediated injury through Bim, Bax and the fission protein Drp1. Neurobiol Dis 2006;23:11-22.

89. Siau C, Bennett GJ. Dysregulation of cellular calcium homeostasis in chemotherapy-evoked painful peripheral neuropathy. Anesth Analg 2006;102:1485-1490.

90. Shu XQ, Mendell LM. Neurotrophins and hyperalgesia. Proc Natl Acad Sci U S A 1999;96:7693-7696.

91. Ogun-Muyiwa P, Helliwell R, McIntyre P, Winter J. Glial cell line derived neurotrophic factor (GDNF) regulates VR1 and substance $P$ in cultured sensory neurons. Neuroreport 1999;10:2107-2111.

92. Hudson LJ, Bevan S, Wotherspoon G, Gentry C, Fox A, Winter J. VR1 protein expression increases in undamaged DRG neurons after partial nerve injury. Eur J Neurosci 2001;13:2105-2114.

93. Zhang XF, Zhu CZ, Thimmapaya R, et al. Differential action potentials and firing patterns in injured and uninjured small dorsal root ganglion neurons after nerve injury. Brain Res 2004;1009: $147-158$.

94. Mansour HH. Protective role of carnitine ester against radiationinduced oxidative stress in rats. Pharmacol Res 2006;54:165-171.

95. Ferraresi R, Troiano L, Roat E, et al. Protective effect of acetylL-carnitine against oxidative stress induced by antiretroviral drugs. FEBS Lett 2006;580:6612-6616.

96. Manfridi A, Forloni GL, Arrigoni-Martelli E, Mancia M. Culture of dorsal root ganglion neurons from aged rats: effects of acetylL-carnitine and NGF. Int J Dev Neurosci 1992;10:321-329.

97. Liu J, Killilea DW, Ames BN. Age-associated mitochondrial oxidative decay: improvement of carnitine acetyltransferase substrate-binding affinity and activity in brain by feeding old rats acetyl-L-carnitine and/or $R$ - $\alpha$-lipoic acid [Erratum in: Proc Natl Acad Sci U S A 2002;99:7184]. Proc Natl Acad Sci U S A 2002; $99: 1876-1881$.

98. Picconi B, Barone I, Pisani A, et al. Acetyl-L-carnitine protects striatal neurons against in vitro ischemia: the role of endogenous acetylcholine. Neuropharmacology 2006;50:917-923.

99. Alves E, Binienda Z, Carvalho F, et al. Acetyl-L-carnitine provides effective in vivo neuroprotection over 3,4-methylenedioximethamphetamine-induced mitochondrial neurotoxicity in the adolescent rat brain. Neuroscience 2009;158:514-523.

100. Fernandez E, Pallini R, Gangitano C, et al. Effects of L-carnitine, L-acetylcarnitine and gangliosides on the regeneration of the transected sciatic nerve in rats. Neurol Res 1989;11:57-62.

101. Mamoulakis D, Galanakis E, Dionyssopoulou E, Evangeliou A, Sbyrakis S. Carnitine deficiency in children and adolescents with type 1 diabetes. J Diabetes Complications 2004;18:271-274.

102. Famularo G, Moretti S, Marcellini S, et al. Acetyl-carnitine deficiency in AIDS patients with neurotoxicity on treatment with antiretroviral nucleoside analogues. AIDS 1997;11:185-190.

103. Ido Y, McHowat J, Chang KC, et al. Neural dysfunction and metabolic imbalances in diabetic rats: prevention by acetyl-Lcarnitine. Diabetes 1994;43:1469-1477.

104. Lowitt S, Malone JI, Salem AF, Korthals J, Benford S. AcetylL-carnitine corrects the altered peripheral nerve function of experimental diabetes. Metabolism 1995;44:677-680.

105. Nakamura J, Koh N, Sakakibara F, et al. Polyol pathway hyperactivity is closely related to carnitine deficiency in the pathogenesis of diabetic neuropathy of streptozotocin-diabetic rats. J Pharmacol Exp Ther 1998;287:897-902.

106. Stevens MJ, Lattimer SA, Feldman EL, et al. Acetyl-L-carnitine deficiency as a cause of altered nerve myo-inositol content, $\mathrm{Na}, \mathrm{K}-\mathrm{ATPase}$ activity, and motor conduction velocity in the streptozotocin-diabetic rat. Metabolism 1996;45:865-872.

107. Sima AA, Ristic H, Merry A, et al. Primary preventive and secondary interventionary effects of acetyl-L-carnitine on diabetic neuropathy in the bio-breeding Worcester rat. J Clin Invest 1996;97:1900-1907.

108. Ohsawa M, Miyata S, Carlsson A, Kamei J. Preventive effect of acetyl-L-carnitine on the thermal hypoalgesia in streptozotocininduced diabetic mice. Eur J Pharmacol 2008;588:213-216.

109. Pisano C, Pratesi G, Laccabue D, et al. Paclitaxel and cisplatininduced neurotoxicity: a protective role of acetyl-L-carnitine. Clin Cancer Res 2003;9:5756-5767.

110. Ghirardi O, Lo Giudice P, Pisano C, et al. Acetyl-L-carnitine prevents and reverts experimental chronic neurotoxicity induced by oxaliplatin, without altering its antitumor properties. Anticancer Res 2005;25:2681-2687.

111. Flatters SJ, Xiao WH, Bennett GJ. Acetyl-L-carnitine prevents and reduces paclitaxel-induced painful peripheral neuropathy. Neurosci Lett 2006;397:219-223.

112. Xiao W, Bennett GJ. Chemotherapy-evoked neuropathic pain: abnormal spontaneous discharge in A-fiber and C-fiber primary afferent neurons and its suppression by acetyl-L-carnitine. Pain 2008; 135:262-270.

113. Piovesan P, Pacifici L, Taglialatela G, Ramacci MT, Angelucci L. Acetyl-L-carnitine treatment increases choline acetyltransferase activity and NGF levels in the CNS of adult rats following total fimbria-fornix transection. Brain Res 1994;633:77-82.

114. Foreman PJ, Perez-Polo JR, Angelucci L, Ramacci MT, Taglialatela G. Effects of acetyl-L-carnitine treatment and stress exposure on the nerve growth factor receptor ( $\left.\mathrm{p} 75^{\mathrm{NGFR}}\right)$ mRNA level in the central nervous system of aged rats. Prog Neuropsychopharmacol Biol Psychiatry 1995;19:117-133.

115. Barhwal K, Hota SK, Prasad D, Singh SB, Ilavazhagan G. Hypoxiainduced deactivation of NGF-mediated ERK1/2 signaling in hippocampal cells: neuroprotection by acetyl-L-carnitine. J Neurosci Res 2008;86:2705-2721.

116. Di Cesare Mannelli L, Ghelardini C, Calvani M, et al. Protective effect of acetyl-L-carnitine on the apoptotic pathway of peripheral neuropathy. Eur J Neurosci 2007;26:820-827.

117. Pettegrew JW, Levine J, McClure RJ. Acetyl-L-carnitine physical-chemical, metabolic, and therapeutic properties: relevance for its mode of action in Alzheimer's disease and geriatric depression. Mol Psychiatry 2000;5:616-632.

118. Jin HW, Flatters SJ, Xiao WH, Mulhern HL, Bennett GJ. Prevention of paclitaxel-evoked painful peripheral neuropathy by acetyl-L-carnitine: effects on axonal mitochondria, sensory nerve fiber terminal arbors, and cutaneous Langerhans cells. Exp Neurol 2008;210:229-237.

119. Chiechio S, Caricasole A, Barletta E, et al. L-Acetylcarnitine induces analgesia by selectively up-regulating mGlu2 metabotropic glutamate receptors. Mol Pharmacol 2002;61:989-996.

120. Chiechio S, Copani A, De Petris L, Morales ME, Nicoletti F, Gereau RW 4th. Transcriptional regulation of metabotropic glutamate receptor $2 / 3$ expression by the NF- $\kappa \mathrm{B}$ pathway in primary dorsal root ganglia neurons: a possible mechanism for the analgesic effect of L-acetylcarnitine. Mol Pain 2006;2:20.

121. Ghelardini C, Galeotti N, Calvani M, Mosconi L, Nicolai R, Bartolini A. Acetyl-L-carnitine induces muscarinic antinociception in mice and rats. Neuropharmacology 2002;43:1180-1187.

122. Di Cesare Mannelli L, Ghelardini C, Calvani M, et al. Neuroprotective effects of acetyl-L-carnitine on neuropathic pain and apoptosis: a role for the nicotinic receptor. J Neurosci Res 2009; 87:200-207.

123. Grandis DD. Tolerability and efficacy of L-acetylcarnitine in patients with peripheral neuropathies: a short-term, open multicentre study. Clin Drug Investig 1998;15:73-79.

124. Evans JD, Jacobs TF, Evans EW. Role of acetyl-L-carnitine in the treatment of diabetic peripheral neuropathy. Ann Pharmacother 2008;42:1686-1691.

125. Sima AA, Calvani M, Mehra M, Amato A; Acetyl-L-Carnitine Study Group. Acetyl-L-carnitine improves pain, nerve regeneration, and vibratory perception in patients with chronic diabetic neuropathy: an analysis of two randomized placebo-controlled trials. Diabetes Care 2005;28:89-94.

126. Bianchi G, Vitali G, Caraceni A, et al. Symptomatic and neurophysiological responses of paclitaxel- or cisplatin-induced neu- 
ropathy to oral acetyl-L-carnitine. Eur J Cancer 2005;41:17461750.

127. Maestri A, De Pasquale Ceratti A, Cundari S, Zanna C, Cortesi E, Crinò L. A pilot study on the effect of acetyl-L-carnitine in paclitaxel- and cisplatin-induced peripheral neuropathy. Tumori 2005;91:135-138.

128. Hart AM, Wilson AD, Montovani C, et al. Acetyl-L-carnitine: a pathogenesis based treatment for HIV-associated antiretroviral toxic neuropathy. AIDS 2004;18:1549-1560.

129. Herzmann C, Johnson MA, Youle M. Long-term effect of acetylL-carnitine for antiretroviral toxic neuropathy. HIV Clin Trials 2005;6:344-350.

130. Valcour V, Yeh TM, Bartt R, et al. Acetyl-L-carnitine and nucleoside reverse transcriptase inhibitor-associated neuropathy in HIV infection. HIV Med 2009;10:103-110.

131. Bordet T, Buisson B, Michaud M, et al. Identification and characterization of cholest-4-en-3-one, oxime (TRO19622), a novel drug candidate for amyotrophic lateral sclerosis. J Pharmacol Exp Ther 2007;322:709-720.

132. Rostovtseva TK, Sheldon KL, Hassanzadeh E, et al. Tubulin binding blocks mitochondrial voltage-dependent anion channel and regulates respiration. Proc Natl Acad Sci U S A 2008;105: 18746-18751.

133. Bordet T, Buisson B, Michaud M, et al. Specific antinociceptive activity of cholest-4-en-3-one, oxime (TRO19622) in experimental models of painful diabetic and chemotherapy-induced neuropathy. J Pharmacol Exp Ther 2008;326:623-632.

134. Pabbidi RM, Cao DS, Parihar A, Pauza ME, Premkumar LS. Direct role of streptozotocin in inducing thermal hyperalgesia by enhanced expression of transient receptor potential vanilloid 1 in sensory neurons. Mol Pharmacol 2008;73:995-1004.

135. Simiand J, Keane PE, Barnouin MC, Keane M, Soubrié P, Le Fur G. Neuropsychopharmacological profile in rodents of SR $57746 \mathrm{~A}$, a new, potent $5-\mathrm{HT}_{1 \mathrm{~A}}$ receptor agonist. Fundam Clin Pharmacol 1993;7:413-427.

136. Labie C, Lafon C, Marmouget C, et al. Effect of the neuroprotective compound SR57746A on nerve growth factor synthesis in cultured astrocytes from neonatal rat cortex. Br J Pharmacol 1999;127:139-144.

137. Fournier J, Steinberg R, Gauthier T, et al. Protective effects of SR $57746 \mathrm{~A}$ in central and peripheral models of neurodegenerative disorders in rodents and primates. Neuroscience 1993;55:629641.

138. Cassidy J, Bjarnason GA, Hickish T. Randomized double blind (DB) placebo (Plcb) controlled phase III study assessing the efficacy of xaliproden $(\mathrm{X})$ in reducing the cumulative peripheral sensory neuropathy (PSN) induced by the oxaliplatin (Ox) and 5-FU/LV combination (FOLFOX4) in firstline treatment of patients (pts) with metastatic colorectal cancer (MCRC). J Clin Oncol 2006;24 Suppl 18S:3507 (abstract).

139. Susman E. Xaliproden lessens oxaliplatin-mediated neuropathy. Lancet Oncol 2006;7:288.
140. Kakinoki B, Sekimoto S, Yuki S, et al. Orally active neurotrophin-enhancing agent protects against dysfunctions of the peripheral nerves in hyperglycemic animals. Diabetes 2006;55:616621.

141. Calcutt NA, Freshwater JD, Hauptmann N, Taylor EM, Mizisin AP. Protection of sensory function in diabetic rats by Neotrofin. Eur J Pharmacol 2006;534:187-193.

142. Gavish M, Bachman I, Shoukrun R, et al. Enigma of the peripheral benzodiazepine receptor. Pharmacol Rev 1999;51:629-650.

143. Galiegue S, Tinel N, Casellas P. The peripheral benzodiazepine receptor: a promising therapeutic drug target. Curr Med Chem 2003;10:1563-1572.

144. Veenman L, Papadopoulos V, Gavish M. Channel-like functions of the 18-kDa translocator protein (TSPO): regulation of apoptosis and steroidogenesis as part of the host-defense response. Curr Pharm Des 2007;13:2385-2405.

145. Vin V, Leducq N, Bono F, Herbert JM. Binding characteristics of SSR180575, a potent and selective peripheral benzodiazepine ligand. Biochem Biophys Res Commun 2003;310:785-790.

146. Ferzaz B, Brault E, Bourliaud G, et al. SSR180575 (7-chloro$N, N$,5-trimethyl-4-oxo-3-phenyl-3,5-dihydro-4H-pyridazino[4,5$b$ indole-1-acetamide), a peripheral benzodiazepine receptor ligand, promotes neuronal survival and repair. J Pharmacol Exp Ther 2002;301:1067-1078.

147. Gibson GE, Karuppagounder SS, Shi Q. Oxidant-induced changes in mitochondria and calcium dynamics in the pathophysiology of Alzheimer's disease. Ann N Y Acad Sci 2008;1147: 221-232.

148. Apfel SC, Schwartz S, Adornato BT, et al.; rhNGF Clinical Investigator Group. Efficacy and safety of recombinant human nerve growth factor in patients with diabetic polyneuropathy: a randomized controlled trial. JAMA 2000;284:2215-2221.

149. Schifitto G, Yiannoutsos C, Simpson DM, et al.; AIDS Clinical Trials Group Team 291. Long-term treatment with recombinant nerve growth factor for HIV-associated sensory neuropathy. Neurology 2001;57:1313-1316.

150. Wellmer A, Misra VP, Sharief MK, Kopelman PG, Anand P. A double-blind placebo-controlled clinical trial of recombinant human brain-derived neurotrophic factor (rhBDNF) in diabetic polyneuropathy. J Peripher Nerv Syst 2001;6:204-210.

151. Evans SR, Simpson DM, Kitch DW, et al. A randomized trial evaluating Prosaptide for HIV-associated sensory neuropathies: use of an electronic diary to record neuropathic pain. PLoS One 2007;2:e551.

152. Reljanovic M, Reichel G, Rett K, et al. Treatment of diabetic polyneuropathy with the antioxidant thioctic acid ( $\alpha$-lipoic acid): a two year multicenter randomized double-blind placebo-controlled trial (ALADIN II). Alpha Lipoic Acid in Diabetic Neuropathy. Free Radic Res 1999;31:171-179.

153. Ziegler D, Ametov A, Barinov A, et al. Oral treatment with $\alpha$-lipoic acid improves symptomatic diabetic polyneuropathy: the SYDNEY 2 trial. Diabetes Care 2006;29:2365-2370. 